\title{
COMUNICAÇÃO
}

\section{AVALIAÇÃO DE UM SISTEMA DE IRRIGAÇÃO AUTOPROPELIDO AṔLICANDO ÁGUA RESIDUÁRIA DE SUINOCULTURA}

\author{
Evaluation of a self propelled irrigation system for application of swine wastewater
}

\author{
Antônio Carlos Barreto', Cláudio Milton Montenegro Campos²
}

\begin{abstract}
RESUMO
Este experimento foi conduzido na Unidade I do Centro Federal de Educação Tecnológica de Uberaba (CEFET-Uberaba), em Uberaba, MG, durante o ano de 2006. Conduziu esse experimento, com o objetivo de avaliar a influência da concentração de sólidos totais contidos na água residuária de suinocultura: nas perdas de cargas ocorridas no sistema, na uniformidade de distribuição, na distribuição de sólidos totais ao longo do raio de alcance do aspersor, no raio de alcance do aspersor. Os tratamentos constaram das concentrações de sólidos totais contidos em cada camada da lagoa retirada durante o ensaio. Utilizou-se um sistema de irrigação autopropelido da marca Metal Lavras, modelo mini 63/150, equipado com um canhão da marca Plona modelo RL 250 e um sistema de bombeamento composto por uma bomba da marca Schneider modelo MSA-22 R 1 1/4" acoplada a um motor trifásico de $15 \mathrm{cv}$. As perdas de carga foram influenciadas diretamente pela concentração dos sólidos contidos na água residuária, chegando a acréscimos de $30,77 \%$ na adutora, $13,59 \%$ na turbina e $22,02 \%$ na mangueira, para a maior concentração de sólidos avaliada em relação a água sem resíduo. Na uniformidade de distribuição e no raio de alcance do aspersor, não houve influência significativa da concentração de sólidos. Na distribuição de sólidos ao longo do raio de alcance do aspersor, observou-se uma maior concentração nos coletores mais afastados do aspersor.
\end{abstract}

Termos para indexação: Reuso de água; equipamento de irrigação; perda de carga.

\section{ABSTRACT}

This experiment was carried out at Unit I at the Federal Technological Education Center in Uberaba (CEFET-Uberaba-MG), during the year of 2006. The aim was to evaluate the influence of solids concentration in swine wastewater on charge losses of the irrigation system, on water distribution uniformity, on distribution of solids along the sprinkler radius of throw. The treatment levels were solid concentration at different depths of a water pond. The irrigation self propelled system is manufactured by Metal Lavras, model mini 63/150, with a gun sprinkler model Plona RL 250 and a pump system with a Schneider unit model MSA-22R 1/14" with a three phase electrical engine $15 \mathrm{HP}$. The charge losses were influenced by the solids concentration increasing the losses in $30.77 \%$ at the main pipe, $13.59 \%$ at the turbine and $22.02 \%$ at the plastic hose, for the largest solid concentration compared to water only. At water distribution uniformity and radius of throw statistical differences were not observed. One observed that solid application varied along the radius of throw, being larger quantities applied at the larger distances.

Index terms: Water reuse; irrigation equipment; load loss.

(Recebido em 8 de junho de 2007 e aprovado em 4 de junho de 2008)

A atual expansão da suinocultura tem como principal característica a alta concentração de animais por área. Como conseqüência, se torna uma atividade de baixa qualidade ambiental, poluindo as águas, os solos, afetando a qualidade do ar com emissão de maus odores e pela proliferação de insetos, ocasionando desconforto à população.

O Brasil possui o quarto maior plantel de suínos do mundo com, aproximadamente, 34,5 milhões de cabeças. Deste total, 3,4 milhões estão alojados no estado de Minas
Gerais, onde a atividade tem importante contribuição econômica (ANUALPEC, 2006).

Tendo o Brasil clima favorável e disponibilidade de áreas para um aumento potencial de seu rebanho, deve-se buscar uma forma de manejar adequadamente os dejetos de suínos. Este é o maior desafio para o setor de pesquisas do país, ou seja, garantir o aumento da produção, sem perder a qualidade ambiental.

Muitos estudos vêm sendo realizados na busca da forma correta de destinação dos dejetos líquidos de suínos.

\footnotetext{
${ }^{1}$ Engenheiro Agrícola, Doutor - Departamento de Irrigação e Drenagem - Centro Federal de Educação Tecnológica de Uberaba/CEFET - Rua João Batista Ribeiro, 4000 - Mercês - 38064-790 - Uberaba, MG - barreto@cefetuberaba.edu.br

${ }^{2}$ Engenheiro Civil, Doutor, Professor - Departamento de Engenharia/DEG - Universidade Federal de Lavras/UFLA - Cx. P. 3037 - $37200-000$ - Lavras, MG - cmmcampos@ufla.br
} 
A recomendação técnica é o armazenamento e tratamento em esterqueiras ou lagoas, para posterior uso como fertilizantes nas lavouras (DARTORA, 1998; KONZEN, 2003; OLIVEIRA, 2002).

Existem várias formas de aplicação nas culturas dos dejetos líquidos tratados. Dentre elas, pode-se destacar a aplicação via irrigação por aspersão. Entre os vários sistemas de irrigação por aspersão, destaca-se o equipamento autopropelido que vem sendo utilizado de forma a reduzir a mão-de-obra despendida na aplicação. Este é um equipamento semi-automático, pois possui dispositivo que promove a locomoção do aspersor, enquanto este faz a distribuição do líquido na área irrigada.

Para que a irrigação apresente uniformidade de distribuição satisfatória é necessário conhecer as suas características hidráulicas, bem como as características físicas do líquido a ser distribuído pelo sistema.

A distribuição do dejeto de suíno no campo pode ser realizada de várias formas. Dentre elas, as mais utilizadas são: o tanque mecanizado e o sistema de aspersão. O sistema de distribuição por aspersão permite uma distribuição uniforme do material. Com um mesmo valor de investimento, pode-se fertilizar uma área de até $50 \%$ a mais do que com a utilização de um tanque mecanizado, além de não fornecer limitações relativas a trânsito, em função da topografia (KONZEN, 2003).

Segundo Bernardo (1989), o sistema de irrigação autopropelido consiste em um aspersor de médio ou grande alcance, montado sobre uma carreta com uma unidade acionadora, carretel enrolador de mangueira, o qual pode ser tracionado por meio de cabo de aço ou pela própria mangueira e uma tubulação que faz a conexão da unidade com a linha adutora e o sistema de bombeamento.

Rocha (1998), avaliando equipamento autopropelido da marca IRTEC e modelo 50F/250, verificou valores de perdas de carga na turbina da ordem de 30 mca. Já Rocha (2000), avaliando equipamento da marca Metal Lavras e modelo 90/240, encontrou perda de carga de 9 mca.

Existem várias equações para calcular a uniformidade de aplicação de um sistema de irrigação, dentre estas, Bernardo (1989) cita a equação de cálculo do coeficiente de uniformidade, proposta por Christinasen (1942).

$\mathrm{Na}$ literatura, existem diversos modelos para estimar a perda de carga distribuída em condutos forçados, sendo agrupados em três categorias: correlações gráficas, equações empíricas e aqueles que estimam o fator de atrito existente entre o líquido escoante e as paredes da tubulação (AZEVEDO NETTO et al., 1998). Sampaio (1999) propôs um modelo para o cálculo da perda de carga em função da concentração de sólidos totais e outros parâmetros.

Com base no exposto, conduziu-se este trabalho, com o objetivo determinar a perda de carga distribuída nas tubulações que compõem o sistema de irrigação autopropelido; verificar a influência da concentração de sólidos totais na uniformidade de distribuição do sistema de irrigação e a distribuição de sólidos ao longo do raio de alcance do aspersor e determinar o raio de alcance do aspersor.

Para a avaliação de um sistema de irrigação autopropelido, aplicando-se água residuária de suinocultura, foram conduzidos ensaios do equipamento em campo, numa área experimental do Centro Federal de Educação Tecnológica situado em Uberaba (CEFETUberaba), MG, na região do Triângulo Mineiro. Sua localização geográfica é definida pelas coordenadas 19³9'33" de latitude Sul e 4757'33" de longitude Oeste, com altitude média de $805 \mathrm{~m}$.

O modelo de criação de suínos do CEFET-Uberaba é de ciclo completo, com um rebanho estabilizado de 40 matrizes, que produzem um volume médio diário de dejetos de $6 \mathrm{~m}^{3}$. O método de tratamento utilizado para estabilização da matéria orgânica é o de lagoas de estabilização, constituído por duas lagoas com volume individual de aproximadamente $500 \mathrm{~m}^{3}$. O tempo de detenção hidráulica para sua estabilização foi de 30 dias, durante os quais o líquido era agitado a cada dois dias, por meio de um sistema de bombeamento e injeção do mesmo em diferentes pontos da lagoa, buscando-se acelerar o processo por meio de homogeneização.

O sistema de bombeamento foi instalado sobre uma balsa, buscando-se diminuir a altura de sucção. O conjunto motobomba utilizado foi da marca Schneider modelo MSA22R 11/4" x 1", sendo acionado por um motor elétrico trifásico de $15 \mathrm{cv}$, tendo como dispositivo de acionamento uma chave de partida estrela triângulo do tipo alavanca. A adutora foi constituída de tubo de aço zincado com diâmetro nominal $108 \mathrm{~mm}$. A tubulação empregada na adutora possuía tempo de uso superior a 15 anos, portanto, com rugosidade interna possivelmente alterada.

O equipamento de irrigação utilizado nos ensaios de avaliações foi do tipo autopropelido, da marca Metal Lavras e modelo Hidro-Roll 63/150 série mini, com mangueira de 150 metros de comprimento, diâmetro $63 \mathrm{~mm}$ e espessura da parede da mangueira, $4,7 \mathrm{~mm}$; redutor de velocidade acionado por engrenagens com duas velocidades, acionamento do carretel enrolador por pinhão e cremalheira; sistema de regulagem da velocidade de recolhimento da mangueira eletrônico, fim de curso, e o 
carroaspersor, onde foi instalado o aspersor da marca Plona, modelo RL 250.

Os tratamentos foram considerados nas profundidades de 0 a $20 \mathrm{~cm}, 20$ a $40 \mathrm{~cm}, 40$ a $60 \mathrm{~cm}, 60$ a 80 $\mathrm{cm}, 80$ a 100,100 a $120 \mathrm{~cm}, 120$ a $140 \mathrm{~cm}, 140$ a 160,160 a $180 \mathrm{~cm}, 180$ a $200 \mathrm{~cm}, 200$ a $220 \mathrm{~cm}$ e 220 a $240 \mathrm{~cm}$, sendo um total de doze tratamentos ao longo do perfil da lagoa de captação, sendo a concentração de sólidos totais existente em cada camada considerada o tratamento. Foram realizadas três repetições para cada tratamento, perfazendo um total de 36 avaliações. Deste total, três ensaios com água sem sólidos foram realizados em momentos distintos. Os ensaios de campo foram conduzidos conforme estabelecido pelas normas de qualidade internacional ISO 8224/1 (ISO, 2003) e ISO 7749/ 2 (ISO, 1990), que descrevem a metodologia de avaliação de equipamentos de irrigação autopropelido.

Para a determinação da perda de carga nas tubulações, foram utilizadas tomadas de pressão metálica do tipo engate rápido, instaladas no início e no fim da tubulação, utilizando um manômetro tipo Bourdon (glicerina previamente calibrado e sempre escorvado com água sem sólidos para evitar entupimentos.

Para a determinação do coeficiente de uniformidade, foram instaladas três linhas de coletores perpendiculares ao movimento do carro aspersor e espaçadas de $6 \mathrm{~m}$ entre si. A primeira linha foi colocada a $70 \mathrm{~m}$ do carretel enrolador, no início de cada ensaio. Em cada linha foram instalados 24 coletores, sendo 12 para cada lado do carreador central em que o primeiro estava instalado a 1,5 $\mathrm{m}$ do eixo central do carroaspersor e os demais com espaçamento de $3 \mathrm{~m}$.

Durante a determinação das lâminas coletadas em cada ensaio para o cálculo do coeficiente de uniformidade de Christiansen, os volumes dos coletores $2^{\circ}, 5^{\circ}$ e $8^{\circ}$, de cada lado do carreador central, foram armazenados em recipientes devidamente identificados, para a determinação da concentração de sólidos totais, sólidos fixos e sólidos voláteis em cada amostra e, em seguida, utilizando o método do balão volumétrico determinou o peso específico médio do fluido para cada tratamento.

O raio de alcance do aspersor, em cada tratamento, foi obtido pela distância média entre o aspersor e os coletores que receberam lâmina mínima de $0,25 \mathrm{~mm} \mathrm{~h}^{-1}$, conforme estabelece a norma ISO 7749/2 (ISO, 1990).

Na Tabela 1, são mostrados os valores médios de perda de carga medidos na tubulação adutora em função da concentração de sólidos totais contidos na água residuária, bem como, o percentual de acréscimo. Verificase que houve um acréscimo de até $30,77 \%$ na perda de carga para o tratamento de maior concentração de sólidos em relação à perda de carga do tratamento sem resíduo.

Tabela 1 - Perda de carga na adutora de 180 em aço zincado, em função da concentração de sólidos totais contidos na água residuária. CEFET, Uberaba, 2006.

\begin{tabular}{cccc}
\hline $\begin{array}{c}\text { Sólidos } \\
\text { totais } \\
\left(\text { mg L }^{-1}\right)\end{array}$ & $\begin{array}{c}\text { Perda de } \\
\text { carga } \\
\text { adutora } \\
(\text { mca })\end{array}$ & $\begin{array}{c}\% \text { de } \\
\text { acréscimo }\end{array}$ & $\begin{array}{c}\text { Coeficiente } \\
\text { de atrito(C) }\end{array}$ \\
\hline $\begin{array}{c}540 \text { (água) } \\
2453\end{array}$ & 5,33 & - & 83,0 \\
2913 & 5,51 & 3,38 & 90,0 \\
3725 & 5,66 & 6,19 & 83,5 \\
4755 & 5,83 & 9,38 & 77,0 \\
5033 & 6,00 & 12,57 & 72,5 \\
7094 & 6,05 & 13,51 & 71,0 \\
7542 & 6,31 & 18,39 & 66,0 \\
11335 & 6,33 & 18,76 & 66,6 \\
15538 & 6,61 & 24,02 & 66,2 \\
20513 & 6,76 & 26,83 & 61,5 \\
34169 & 6,88 & 29,08 & 60,0 \\
\hline
\end{tabular}

Observando a Tabela 1, constata-se que os coeficientes de atrito " $C$ " do modelo de Hazen-Williams modificado, modelo apresentado por Sampaio (1999), ajustado à situação de rugosidade da tubulação utilizada nos ensaios onde encontra-se um acréscimo neste valor para os tratamentos com menor concentração e posteriores decréscimos nos valores do coeficiente de atrito para as maiores as concentrações de sólidos, o que explica a diminuição da perda de carga ocorrida na adutora.

$\mathrm{O}$ valor encontrado para o tratamento sem resíduo na água é semelhante ao valor proposto para Azevedo Netto et al. (1998) para tubos com vinte anos de uso, sendo este fato atribuído ao aumento da rugosidade interna na tubulação provocada pela formação de nódulos.

Encontram-se na Tabela 2 os valores médios de perda de carga determinada na turbina e o percentual de acréscimo em relação ao tratamento sem sólidos, podendose observar um acréscimo da perda de carga da ordem de $13,59 \%$ para o tratamento com maior concentração de sólidos totais.

Rocha $(1998,2000)$ relata valores semelhantes para a perda de carga provocada pela turbina ao operar com água sem sólidos e concluem ainda que este valor diminui à medida que o equipamento recolhe a mangueira. 
Tabela 2 - Perda de carga determinada na turbina. CEFET, Uberaba, MG, 2006.

\begin{tabular}{ccc}
\hline $\begin{array}{c}\text { Sólidos totais } \\
\left(\mathrm{mg} \mathrm{L}^{-1}\right)\end{array}$ & $\begin{array}{c}\text { Perda de carga } \\
\text { na Turbina } \\
(\mathrm{mca})\end{array}$ & \% de acréscimo \\
\hline 540 (Água) & 9,74 & - \\
2453 & 9,81 & 0,70 \\
2913 & 9,90 & 1,61 \\
3725 & 9,93 & 1,99 \\
4755 & 10,19 & 4,65 \\
5033 & 10,21 & 4,79 \\
7094 & 10,28 & 5,51 \\
7542 & 10,30 & 5,74 \\
11335 & 10,48 & 7,55 \\
15538 & 10,60 & 8,80 \\
20513 & 10,83 & 11,21 \\
34169 & 11,06 & 13,59 \\
\hline
\end{tabular}

Na Tabela 3, são mostrados os valores da perda de carga medida na mangueira, em função da concentração de sólidos totais contidos em cada tratamento e o percentual de acréscimo desta em relação ao tratamento sem resíduo, onde é observado um acréscimo de 22,02\% no valor da perda de carga. $\mathrm{O}$ aumento neste parâmetro pode ser atribuído ao do maior atrito entre as partículas e as paredes da tubulação e entre as próprias partículas.
Tabela 3 - Perda de carga medida na mangueira em função da concentração de sólidos totais em cada tratamento. CEFET, Uberaba, MG, 2006.

\begin{tabular}{ccc}
\hline $\begin{array}{c}\text { Sólidos totais } \\
\left(\mathrm{mg} \mathrm{L}^{-1}\right)\end{array}$ & $\begin{array}{c}\text { Perda de carga } \\
\text { na Mangueira } \\
(\mathrm{mca})\end{array}$ & \% de acréscimo \\
\hline 540 (Água) & 10,68 & - \\
2453 & 10,79 & 1,08 \\
2913 & 10,84 & 1,54 \\
3725 & 10,86 & 1,69 \\
4755 & 11,14 & 4,37 \\
5033 & 11,28 & 5,64 \\
7094 & 11,50 & 7,71 \\
7542 & 11,52 & 7,93 \\
11335 & 11,77 & 10,19 \\
15538 & 11,96 & 12,05 \\
20513 & 12,73 & 19,22 \\
34169 & 13,03 & 22,02 \\
\hline
\end{tabular}

Para a uniformidade de distribuição foi avaliado o coeficiente de uniformidade de Christiansen, sendo estes valores apresentados na Tabela 4 , em que observam-se valores variando de $62 \%$ a $88 \%$, sendo os menores encontrados para os espaçamentos 36 e $42 \mathrm{~m}$ entre carreadores de irrigação.

Tabela 4 -Coeficientes de uniformidade de Christiansen para diferentes espaçamentos entre faixas de irrigação simuladas. CEFET, Uberaba, MG, 2006.

\begin{tabular}{cccccc}
\hline \multirow{2}{*}{ Concentração de sólidos (mg L $\left.{ }^{-1}\right)$} & \multicolumn{5}{c}{ Espaçamento entre as faixas (m) } \\
\hline 540 (água) & 30 & 36 & 42 & 48 & 54 \\
2453 & 87,10 & 72,01 & 70,05 & 78,66 & 84,95 \\
2913 & 80,68 & 76,29 & 77,82 & 82,09 & 75,12 \\
3725 & 85,09 & 74,90 & 72,05 & 79,51 & 79,65 \\
4755 & 71,42 & 62,33 & 69,74 & 80,01 & 74,60 \\
5033 & 72,34 & 70,91 & 80,89 & 83,76 & 73,08 \\
7094 & 75,74 & 66,35 & 73,04 & 76,87 & 78,81 \\
7542 & 83,58 & 74,59 & 76,39 & 83,02 & 79,43 \\
11335 & 82,61 & 79,02 & 78,01 & 79,30 & 76,74 \\
15538 & 80,29 & 76,00 & 78,01 & 82,22 & 77,04 \\
20513 & 85,27 & 73,15 & 73,12 & 81,81 & 81,26 \\
34169 & 80,25 & 77,80 & 77,57 & 78,35 & 74,79 \\
\hline
\end{tabular}


Para os espaçamentos 36 e $42 \mathrm{~m}$ encontrou os menores valores de CUC, o que também foi observado por Prado (2004) em seu trabalho de avaliação do mesmo equipamento.

Rocha $(1998,2000)$ encontrara valores similares para o CUC em seus respectivos trabalhos, para sistemas de irrigação semelhantes ao avaliado.

A concentração de sólidos totais contidos no fluido não influenciou o CUC para um mesmos espaçamento entre as faixas de irrigação conforme a Tabela 4.

Na Figura 1, estão representadas as distribuições de sólidos totais e frações ao longo do raio do aspersor para o tratamento cuja concentração de sólidos totais foi de $34169 \mathrm{mg} \mathrm{L}^{-1}$. Observa-se que houve uma concentração maior de sólidos no coletor mais afastado do aspersor, sendo este fato atribuído à diferença de peso específico da água e das partículas sólidas presentes no dejeto; os demais tratamentos seguiram a mesma tendência.

Em estudo da distribuição de gotas por aspersor montado em um sistema autopropelido, Rocha (1998) verificou uma distribuição de gotas similar à distribuição de sólidos da Figura 1.

Na Tabela 5, são apresentados os valores dos raios de alcance produzidos pelo aspersor, em função da concentração de sólidos totais contidos nos tratamento, não apresentando diferença significativa entre os tratamentos. Valores similares são apresentados por Prado (2004), para um aspersor trabalhando com água sem resíduo.

A Figura 2 representa o perfil médio de distribuição pelo aspersor para o tratamento $540 \mathrm{mg} \mathrm{L}^{-1}$ (água sem resíduo) e $34169 \mathrm{mg} \mathrm{L}^{-1}$, em que pode-se observar uma semelhança entre os perfis; os demais tratamentos apresentaram tendência semelhante. As diferenças entre os perfis podem ser explicadas pela diferença da massa específica da água e a água residuária.

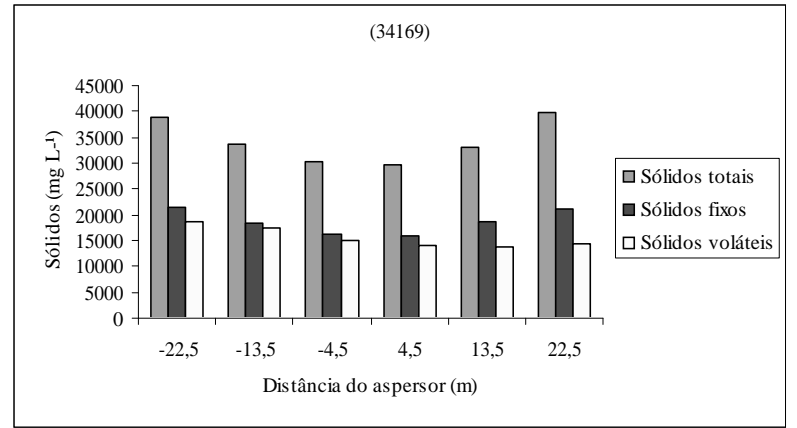

Figura 1 - Distribuição de sólidos ao longo do raio de alcance do aspersor. CEFET, Uberaba, MG, 2006.

Tabela 5 - Raio de alcance do aspersor em função da concentração de sólidos totais. CEFET, Uberaba, MG, 2006.

\begin{tabular}{cc}
\hline $\left.\begin{array}{c}\text { Concentração de sólidos } \\
\text { totais (mg L }\end{array}\right)$ & Raio de alcance $(\mathrm{m})$ \\
\hline $540($ Água) & 30,0 \\
2453 & 30,1 \\
2913 & 30,5 \\
3725 & 30,0 \\
4755 & 30,0 \\
5033 & 30,1 \\
7094 & 30,2 \\
7542 & 30,5 \\
11335 & 30,5 \\
15538 & 30,5 \\
20513 & 30,5 \\
34169 & 31,0 \\
\hline
\end{tabular}

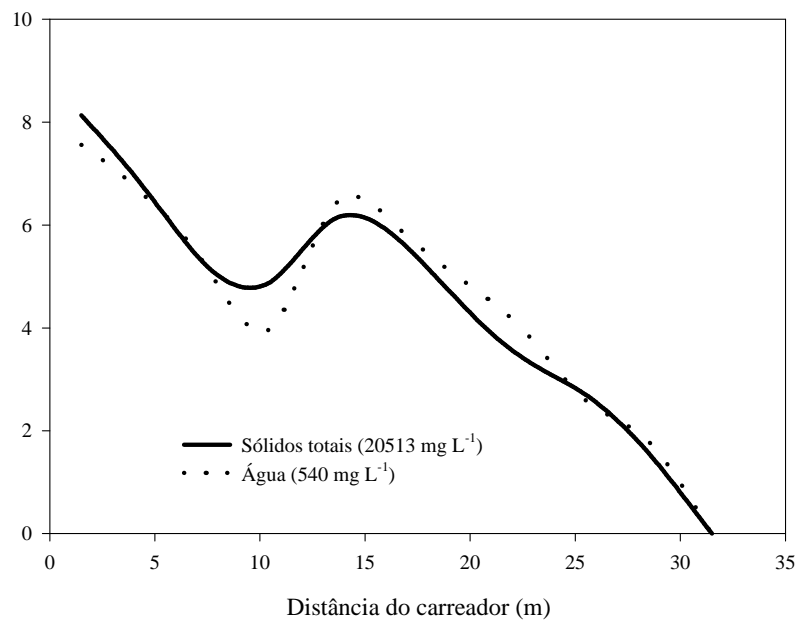

Figura 2 - Representação gráfica da aplicada pelo equipamento aplicando água e água residuária. CEFET, Uberaba, MG, 2006. 
A perda de carga nos componentes que compõem o sistema de irrigação autopropelido é influenciada pela concentração de sólidos totais, quando adotado o modelo Hazen-Williams modificado.

Não há diferenças significativas entre os coeficientes de uniformidade de Christiansen em função da concentração de sólidos totais contidos na água residuária de suinocultura, para as condições dos ensaios.

A concentração de sólidos é maior no extremo do raio de alcance do aspersor, portanto uma distribuição desuniforme é decorrente do peso específico do material que dá maior velocidade final às gotas.

\section{REFERÊNCIAS BIBLIOGRÁFICAS}

ANUALPEC. Anuário da pecuária brasileira. São Paulo: Instituto FNP, 2006. 369 p.

AZEVEDO NETTO, J. M.; FERNANDEZ, M. F.; ARAÚJO, R. de; ITO, A. E. Manual de hidráulica. 8. ed. São Paulo: E. Blücher, 1998. 669 p.

BERNARDO, S. Manual de irrigação. 5. ed. Viçosa: UFV, 1989. $596 \mathrm{p}$.

CHRISTIANSEN, J. E. Irrigation by sprinkler. Berkeley: Califórnia Agricultural Station, 1942. 124 p.

DARTORA, V.; PERDOMO, C. C.; TUMELERO, I. L. Manejo de dejetos de suínos. Concórdia: EmbrapaCNPSA, 1998. 33 p. (Bipers, 11).

INTERNATIONAL ORGANIZATION FOR STANDARTIZATION. ISO-7749/2: Irrigation equipament: rotating sprinklers: part. 2: uniformity of distribution and test methods. Switzerland, 1990. 8 p.

INTERNATIONAL ORGANIZATION FOR

STANDARTIZATION. ISO-8224/1: traveller irrigation machines: part 1: laboratory and field test methods. Switzerland, 2003. 35 p.

KONZEN, E. A. Aproveitamento de dejetos líquido de suínos para fertirrigação e fertilização de grandes culturas. Sete Lagoas: Embrapa-CNPMS, 2003. 11 p. (Circular técnica, 32).

OLIVEIRA, P. A. V.Produção e manejo de dejetos de suínos. Concórdia: Embrapa-CNPSA, 2002. 18 p.

PRADO, G. do. Simulasoft. Versão 2.1. Lavras: UFLA/ DEG, 2004. CD-ROM.

ROCHA, F. A. Desempenho de um equipamento de irrigação autopropelido em condições de campo. 2000. 80 p. Dissertação (Mestrado em Irrigação e Drenagem) Universidade Federal de Lavras, Lavras, 2000.

ROCHA, W. W. Influência de ângulos setoriais e pressão de serviço na uniformidade de distribuição de água de um equipamento autopropelido. 1998. 46 p. Dissertação (Mestrado em Irrigação e Drenagem) Universidade Federal de Lavras, Lavras, 1998.

SAMPAIO, S. C. Perda de carga em tubulações comerciais utilizando como fluido circulante águas residuárias da bovinocultura e suinocultura. 1999. $168 \mathrm{f}$. Tese (Doutorado em Irrigação e Drenagem) Universidade Federal de Viçosa, Viçosa, 1999. 